\section{A proporcionalidade como limite jurídico ao direito negocial}

\author{
ThE PROPORTIONALITY AS LEGAL LIMIT TO \\ BUSINESS LAW \\ * Lucas Augusto da Silva Zolet \\ ** Fausto Santos de Morais
}

Resumo: Este trabalho propõe o estudo da máxima da proporcionalidade e suas máximas parciais, sobretudo da perspectiva do Direito Negocial e na esfera da limitação jurídica pela proporcionalidade ao exercício de liberdades comerciais. $\mathrm{O}$ emprego constante da máxima da proporcionalidade, como fundamento das decisões judiciais, sem o devido rigor metodológico, provoca um debate acerca da utilização da Teoria dos Direitos Fundamentais como mera referência retórica, compreendendo a crítica da fundamentação judicial incompleta da máxima da proporcionalidade, o qual por meio das decisões judiciais pode assumir um caráter distinto ou subvertido daquele previsto na doutrina de Robert Alexy.

Palavras-chave: Máxima da proporcionalidade; Direitos fundamentais; Decisão judicial; Robert Alexy.

Abstract: This paper aims to study the maximum of proportionality and its maximum partial, above all from the perspective of Business Law and in the sphere of legal limitations for the exercise of commercial freedoms. The constant use of the maximum of proportionality, as a ground of judicial decisions, without proper methodological rigor, provokes a debate about the use of the Theory of Fundamental Rights as mere rhetoric reference, including criticism of incomplete legal basis for the maximum of proportionality, the which by means of judgments can assume a distinct or subverted character that provide for doctrine of Robert Alexy.

Keywords: Maximum of proportionality; Fundamental rights; Judicial decision; Robert Alexy. 


\section{INTRODUÇÃO}

O Direito Negocial, como expressão das relações normativas que envolvem os negócios jurídicos, possui uma ligação direta com as transitoriedades advindas das atividades humanas. Em outras palavras, significa dizer que as eventuais crises econômicas podem ser consideradas crises do Direito e, por conseguinte, crises da humanidade.

Nesse contexto, o Direito Negocial, revestido pelas ideias constitucionais, tem a função de dirimir problemas jurídicos contemporâneos, sobretudo oriundos das práticas econômicas e suas particularidades. Essa função cabe ao Direito Negocial porque não se pode acolher posicionamento distinto daquele o qual defende o papel do sistema jurídico como fundamento da ideia de justiça social, especialmente para fins de promoção do bem-estar coletivo.

Com efeito, ao debater acerca do papel do Direito Negocial para um cenário de emancipação humana, não é possível chegar a outra conclusão se não àquela em que as práticas comerciais devem ser englobadas pelos direitos fundamentais. Esses direitos correspondem aos próprios fundamentos da busca pela solução das desigualdades sociais.

O progresso da sociedade, portanto, exige atenção do Direito aos problemas da saúde pública, dos prejuízos ambientais e da prevalência do compromisso com os direitos humanos. Essas questões não podem ser enfrentadas isoladamente pelo Direito, mas reconhece-se que essa doutrina tem papel fundamental no enfrentamento destes problemas. Logo, urge que o movimento jurídico seja englobado pelo saber interdisciplinar na maior medida possível.

É nesse sentido que o estudo da aplicação e interpretação do direito positivo se mostra relevante. Melhor dizendo, faz-se necessário uma investigação científica acerca dos métodos de solução dos casos judiciais para que, a partir do conhecimento adquirido, seja possível apontar o caminho tomado pela ordem jurídica.

Inevitável se faz, portanto, o estudo dos direitos fundamentais, com base na concepção doutrinária de Robert Alexy, especialmente uma pesquisa focada no uso problemático da máxima da proporcionalidade pelos tribunais brasileiros. Essa preocupação científica está centrada na crítica acerca da utilização de doutrinas internacionais como meio racional de solucionar casos jurídicos que envolvem conflitos entre princípios constitucionais e direitos fundamentais. 
Nesse sentido, muitos julgados desconsideram a problemática acerca da compatibilidade metodológica entre algumas doutrinas estrangeiras e o ordenamento nacional, por exemplo, fazendo uso da proporcionalidade como mera ferramenta retórica ao ato de decidir. Logo, não são poucas as decisões que concedem sentido distinto ao conceito proposto por Alexy para a máxima da proporcionalidade.

Mediante uma análise dos fundamentos teóricos da Teoria dos Direitos Fundamentais, sobretudo por meio da máxima da proporcionalidade, bem como pela compreensão das concepções da ponderação, o presente estudo tem o objetivo geral de identificar elementos teóricos acerca da máxima da proporcionalidade e suas máximas parciais.

Outro objetivo central da presente pesquisa é apresentar a análise do caso enfrentado pelo Tribunal Regional Federal da $4^{\mathrm{a}}$ Região - TRF4 ${ }^{1}$ acerca do uso do da proporcionalidade como limite à liberdade de expressão comercial, à livre iniciativa e à intervenção do Estado no direito privado. Essa decisão foi escolhida porque é considerada uma decisão histórica ao longo dos 25 anos do TRF4, bem como em face que o caso envolve um conflito de proposições jurídicas privadas e públicas, sobretudo acerca de diferentes temas relacionados ao Direito Negocial.

Nesse trilhar, movido pelo método fenomenológico-hermenêutico², mediante a revisão bibliográfica ${ }^{3}$, descrever-se-á (a) a relação básica entre Direito Negocial e Direitos Fundamentais, (b) os conceitos teóricos da máxima da proporcionalidade como fórmula lógica para harmonização de princípios colidentes; e (c) apresentar-se-á a decisão judicial supramencionada como exemplo paradigma.

Por fim, pretende-se confirmar a existência da utilização de distintas perspectivas sobre a máxima da proporcionalidade e suas máximas parciais, corroborando o pensamento de que os tribunais nacionais fazem uso da proporcionalidade em um sentido dissonante do proposto por Robert Alexy na Teoria dos Direitos Fundamentais.

${ }^{1}$ Em sede de julgamento da Apelação Cível no 0026898-63.2008.404.7100/RS (BRASIL, 2010).

2 Conforme observa Frijotf Capra (2002, p. 47) a fenomenologia tem como característica essencial a reflexão hermenêutica acerca do tema a ser pesquisado, sobretudo por meio das experiências subjetivas de formação dos juízos. Logo, o método fenomenológico-hermenêutico permite uma capacidade maior de reflexão sistemática acerca dos temas pesquisados.

${ }^{3}$ Conforme observa Pasold (2011, p. 210) a revisão bibliográfica consiste na apresentação científica das "[...] fórmulas e propostas encontradas na Pesquisa Bibliográfica, através de transcrições literais ou paráfrases (sempre com rigorosa referência às fontes utilizadas) devidamente concatenadas para apresentar a lógica de conteúdo do texto em produção". 


\section{O DIREITO NEGOCIAL E OS DIREITOS FUNDAMENTAIS}

No Brasil, a relação contemporânea entre Direito Negocial, Estado e Constituição é múltipla, sobretudo pelo fato de que a Constituição Federal de 1988 é o fundamento basilar do Direito no país, ou seja, trata com primazia e supremacia inúmeros temas, abordagens e casos judiciais amparados na relação entre direitos públicos e privados.

Não obstante a multiplicidade da tutela jurídica constitucional, é preciso considerar a força regulatória que reveste as normas constitucionais. Essa força baseada em poder jurídico e político, invariavelmente, conduz a ideia da Constituição para o sentido de base fundamental para todas as atividades estatais. (QUEIROZ, 2010, p. 47). Logo, no conteúdo emanado da Constituição Federal é possível encontrar toda a essência ou substância jurídica capaz de responder pela tutela dos atos jurídicos-públicos do governo.

Nesse ponto, é passível destacar a doutrina de Goyard-Fabre (2002, p. 126), porque a referida autora sustenta que a Constituição, da abordagem política, consubstancia-se como uma defesa contra os perigos da arbitrariedade que acompanham os representantes dos Poderes e, da abordagem jurídica, é a própria “[...] característica do que se chama o 'Estado de Direito', não só porque ela exclui a arbitrariedade dos governantes, mas porque, por comandar a processualidade interna da ordem jurídica, firma-se também como critério de sua validade".

Nessa linha de pensamento, sobretudo com base no pressuposto da Constituição como referencial normativo de supremacia democrática, inferese que os direitos fundamentais ${ }^{4}$ estão contemplados no centro da ordem jurídica do Estado Democrático de Direito e correspondem a própria racionalização do ordenamento jurídico onde as "[...] forças constituintes e organizadoras da razão garantem a legitimidade da legalidade e da juridicidade". (GOYARD-FABRE, 2002, p. 124).

É por evidente que, a partir da perspectiva lógica constitucional, o Direito Negocial combinado com suas múltiplas vertentes deve considerar os direitos fundamentais como verdadeiros compromissos jurídicos, responsáveis por guiar todas as atividades inerentes da sua própria regulamentação.

\footnotetext{
4 "Por direitos fundamentais entendemos os direitos ou as posições jurídicas ativas das pessoas enquanto tais, individual ou institucionalmente consideradas, assentes na Constituição, seja na Constituição Formal, seja na Constituição material”. (MIRANDA, 2012, p. 9).
} 
Nesse sentido, a doutrinadora portuguesa Cristina Queiroz (2010, p. 49) concede significativa importância aos direitos fundamentais, especialmente por meio da seguinte observação: "Os direitos fundamentais são direitos constitucionais [...] Devem antes ser compreendidos e inteligidos como elementos definidores e legitimadores de toda a ordem jurídica positiva".

Da mesma forma, as experiências sociais erigidas a partir das invocações do Direito Negocial fazem parte da nova construção históricocultural da sociedade, sobretudo com base nas atividades judiciais de promoção e proteção dos direitos fundamentais. Essas atividades são responsáveis por proporcionar ao Direito Negocial uma hipótese de compreensão das relações humanas.

Essa compreensão das relações humanas, que parte do Direito Negocial, está atrelada ao princípio da função social e o da boa-fé objetiva que em síntese procuram prestigiar em maior grau razoável a dignidade da pessoa humana. Esses são os fundamentos do Direito Privado no âmbito da república brasileira.

Por outro lado, para o benefício dos próprios indivíduos, necessário se faz que os direitos fundamentais recebam uma espécie de delineação dos seus limites a depender dos bens concretos a que se propõem a tutelar. Essa é a condição capaz de orientar a experimentalização social das atividades negociais sem subjugação dos direitos fundamentais e com vista a assegurar uma eficácia humana do Direito.

Desde logo, o problema do limite da intervenção estatal nas relações de Direito Negocial ganha espaço e reclama pelo desenvolvimento de um olhar cuidadoso por parte dos juristas, uma vez que a intervenção estatal nas relações privadas está envolvida em uma teia complexa de questões de crescimento humano e desenvolvimento econômico, nesse ponto incluindo o problema dos supostos efeitos nocivos à não autonomia econômica das organizações privadas.

Perante este quadro, convém advertir para a problemática das decisões judiciais, especialmente no que se refere à tutela de casos envolvendo a colisão de direitos fundamentais e princípios constitucionais. Esses casos complexos, pertencentes ao cenário da contemporaneidade do sistema social que envolve o Direito, provém condições que em certa medida podem contribuir para a prática de decisões amplamente discricionárias.

Com base nesse contexto, faz-se crucial destacar a crítica doutrinária acerca do suposto ativismo judicial por parte do Poder Judiciário, o qual, a 
partir de decisões que supostamente não contém o devido rigor e cuidado argumentativo, pode cometer abusos em nome do Direito ${ }^{5}$.

Por isso, é que muitas doutrinas estrangeiras são importadas com o fim de responder aos dilemas jurídicos que se apresentam diariamente no cenário jurídico brasileiro. Uma delas, baseada na Teoria dos Direitos Fundamentais de Robert Alexy, é a máxima da proporcionalidade, utilizado pelos tribunais supostamente como meio capaz de solucionar demandas judiciais envolvendo o conflito de princípios constitucionais, direitos e garantias fundamentais.

Esse caminho, todavia, não decorreu em uma rigorosa aplicação das questões teóricas defendidas por Alexy, na verdade emergiram em dúvidas quanto à prática equivocada da ponderação de princípios. Essa dúvida tem como pressuposto se o uso da proporcionalidade passa simplesmente de mera retórica para possibilitar uma escolha baseada, também, nas convicções pessoais dos julgadores.

É nesse emaranhado de incertezas que se encontram muitas demandas judiciais e o Direito Negocial que na qualidade de grande expoente das relações da sociedade não foge ao exemplo. É justamente com o objetivo argumentativo de ilustrar a referida afirmação que na parte final deste trabalho é apresentada uma pesquisa circunscrita do caso judicial pertencente ao TRF4, o qual tratou sobre a utilização de imagens e advertências obrigatórias nas carteiras de cigarro.

Antes, porém, faz-se necessário introduzir a crítica doutrinária acerca da utilização da máxima da proporcionalidade, bem como introduzir alguns aspectos teóricos acerca da proporcionalidade, desenvolvida por Robert Alexy no âmbito da sua Teoria dos Direitos Fundamentais.

\section{A CRÍTICA DOUTRINÁRIA ACERCA DA UTILIZAÇÃO JUDICIAL DA MÁXIMA DA PROPORCIONALIDADE}

A doutrina de Robert Alexy, sobretudo no que se refere à Teoria dos Direitos Fundamentais, pode ser considerada uma das mais expressivas doutrinas do debate jurídico-filosófico contemporâneo. Não é por outro motivo que, no âmbito da jurisdição e da doutrina brasileira, essa doutrina figura de modo singular, especialmente como base e fundamento teórico de novas concepções jurídicas acerca da proteção dos direitos fundamentais e suas particularidades.

5 Nesse sentido, Streck observa que "O modo mais específico de implementação foi a teoria da argumentação de Robert Alexy, que, entretanto, recebeu uma leitura superficial por parcela considerável da doutrina e dos Tribunais". (STRECK, 2013, p. 286). 
A partir dessa linha de pensamento, é possível trazer a doutrina de Ingo Sarlet (2009) que, ao falar sobre a necessidade de utilização da máxima da proporcionalidade, sugere a aproximação da prática jurídica aos elementos teóricos trazidos pelo pensamento proposto por Alexy:

Tendo em conta que a aplicação dos deveres implica limitação da dimensão subjetiva de direitos, é importante ressaltar a consideração obrigatória do princípio da proporcionalidade, assegurando que todas as medidas tomadas em nome dos deveres (limitação ou redefinição do conteúdo dos direitos fundamentais) estejam ajustadas ao sistema constitucional, resguardando, além disso, sempre o núcleo essencial do direito fundamental afetado. (SARLET, 2009, p. 231).

Nesse contexto, é possível afirmar que no Brasil o uso da proporcionalidade está presente no meio prático jurídico. Em inúmeros casos e ações judiciais, inclusive de significativa expressividade no cenário jurídico do Brasil, os ministros do Supremo Tribunal Federal se utilizaram da máxima da proporcionalidade, sobretudo quando da discussão acerca de ações envolvendo princípios e valores constitucionais ${ }^{6}$.

Nesse sentido, por exemplo, a Ação de Descumprimento de Preceito Fundamental no 54 de 12 de abril de 2012 (BRASIL, 2012). A referida ação, que gerou significativa repercussão no país, ficou conhecida por questionar a inconstitucionalidade da interpretação segundo a qual a interrupção da gravidez de feto anencéfalo é conduta tipificada nos artigos 124, 126 e 128, incisos I e II, do Código Penal.

Ao analisar o caso, a ministra Rosa Weber proferiu voto com base no método da ponderação, o qual depende da aplicação da máxima da proporcionalidade conjugada com suas submáximas. A ministra concluiu pela procedência dos pedidos, sobretudo da perspectiva da máxima da proporcionalidade. (BRASIL, 2012, p. 130).

Todavia, se, por um lado, é possível afirmar que o Judiciário brasileiro promove uma larga utilização dos elementos doutrinários de Robert Alexy, por outro, não é possível dizer que tal utilização observa o necessário rigor na aplicação judicial dos pressupostos científico-metodológicos. Logo, verifica-se um problema entre a aplicação e utilização judicial da Teoria de Alexy. (MORAIS, 2014).

${ }^{6}$ Por exemplo as decisões do Supremo Tribunal Federal: Rcl 2126; Agr 395662; HC 97677; RMS 27920; ADPF 101; ADPF 54; ADI 2240. (STRECK, 2013, p. 290). 
Não se pode, também, ignorar a crítica de que o próprio Supremo Tribunal Federal, desconsidera o todo do construído teórico de Alexy, atinandose tão somente à aplicação do método lógico racional de ponderação, o que não guarda relação adequada com a referida doutrina, porque corresponde apenas a uma pequena parte da proposta do autor. (MORAIS, 2013, p. 296297).

Esse problema decorre no questionamento central a ser verificado no presente estudo, qual seja da possibilidade da utilização insuficiente da Teoria dos Direitos Fundamentais de Robert Alexy, sobretudo no que se refere à máxima da proporcionalidade.

A insuficiência argumentativa por parte do Judiciário decorre em um olhar superficial da proporcionalidade, ou seja, na dificuldade judicial de visualizar a Teoria de Alexy como um sistema, pelo qual a máxima da proporcionalidade deve ser aplicada com rigor e intensa fundamentação, sob o perigo de transformar a ponderação em uma espécie de fragilização da competência legislativa. (LA TORRE, 2006, p. 56).

Dito isso, importa seguir para uma descrição circunscrita e teórica, com base na Teoria dos Direitos Fundamentais de Robert Alexy, da máxima da proporcionalidade e suas máximas parciais para, após, apresentar os problemas jurídicos contidos na pesquisa do estudo de caso.

\section{A MÁXIMA DA PROPORCIONALIDADE E SUAS MÁXIMAS PARCIAIS}

Em primeiro lugar, cumpre mencionar elementos teóricos mínimos sobre a proporcionalidade. Para tanto, salienta-se que a máxima da proporcionalidade tem uma natureza principiológica (mandamentos de otimização), ou seja, existe uma espécie de conexão entre a essência dos direitos fundamentais e o conteúdo material dos princípios incidentes na utilização da teoria da máxima da proporcionalidade. (ALEXY, 2014, p. 188).

Nada obstante, ressalta-se que os conteúdos relacionados aos princípios de direitos constitucionais e fundamentais se implicam de forma dedutiva com o conjunto das premissas da máxima da proporcionalidade e suas máximas parciais. (ALEXY, 1993, p. 111-112).

Com efeito, a máxima da proporcionalidade composta pelas máximas parciais da adequação, da necessidade e da proporcionalidade em sentido estrito, é considerada por Alexy (1993, p. 112) um verdadeiro mandamento 
de ponderação, no qual o alcance real dos princípios dentro de determinado ordenamento jurídico é relativizado e orientado pelas possibilidades jurídicas e fáticas existentes e específicos de tal ordenamento.

Por isso, entende-se que em eventual decisão judicial, caso uma norma de direito fundamental (com caráter ou natureza de princípio) entrar em conflito com um princípio oposto, o julgador deve, necessariamente, observar a possibilidade jurídica de realização de determinado direito fundamental por meio da análise da ponderação de princípios. Todavia, a referida análise somente é corretamente articulada ao passo que corresponder à utilização rigorosa e fundamentada das já mencionadas máximas parciais da proporcionalidade.

A esse propósito, cabe ressaltar que a utilização da máxima parcial da adequação sugere que o meio preterido em determinado caso seja absolutamente adequado para atingir o fim almejado nesta hipótese. Ou seja, para Alexy (1993, p. 114-115) se determinado meio $\left(M_{1}\right)$ não é adequado para promover (de fato) um direito fundamental $\left(\mathrm{F}_{1}\right)$, exigido normativamente por algum princípio $\left(\mathrm{P}_{1}\right)$, então eventual decisão judicial, em análise de caso concreto, deve conhecer que tal meio $\left(\mathrm{M}_{1}\right)$ não é exigido pelo próprio princípio $\left(\mathrm{P}_{1}\right)$. Logo, em análise parcial, determinado princípio de direito fundamental não teria precedência sobre o princípio colidente em caso concreto.

Por outro lado, a necessidade (como postulado de medida mais benéfica) tem o condão de auferir comparativamente se a limitação de um direito fundamental $\left(\mathrm{F}_{2}\right)$, exigido por precedência de direito fundamental $\left(\mathrm{F}_{1}\right)$, é necessária e se não há outros meios (por exemplo $\mathrm{M}_{2}, \mathrm{M}_{3}, \mathrm{M}_{4}$, etc) pelos quais a limitação do direito colidente seja reduzida na sua intensidade.

Assim, Alexy (1993, p. 113) sugere que a necessidade deve ser auferida como uma limitação fática ao alcance dos princípios. Por exemplo, se para a promoção de um direito fundamental $\left(\mathrm{F}_{1}\right)$, baseado no princípio precedente que o normatiza $\left(\mathrm{P}_{1}\right)$, existir pelo menos mais de um meio (como $\mathrm{M}_{1}$ e $\mathrm{M}_{2}$ ) adequados para promover $\mathrm{F}_{1}$, deve ser dado precedência valorativa, na decisão judicial devidamente fundamentada, para o meio que afetará em menor intensidade o alcance do princípio colidente $\left(\mathrm{P}_{2}\right)$.

Logo, pode haver uma infinidade de meios adequados para promoção de determinado direito fundamental $\left(\mathrm{F}_{1}\right)$, para este não terá uma diferença essencial de qual meio deve ser utilizado. Todavia, o princípio de direito fundamental colidente $\left(\mathrm{P}_{2}\right)$, dependendo da escolha dos diferentes meios para promoção de $\mathrm{F}_{1}$, será afetado substancialmente na sua intensidade de proteção, 
por isso a decisão judicial deve ponderar os meios de promoção de $\mathrm{P}_{1}$ menos lesivos para preservar Direito constitucionalmente protegido.

Por último, além da otimização fática realizada pelas máximas parciais da adequação e da necessidade, Alexy (1993, p. 112) condiciona a validade da proporcionalidade à realização da máxima parcial da proporcionalidade em sentido estrito (ponderação ou sopesamento). Essa etapa é responsável por conduzir a análise dos princípios colidentes como mandados de otimização em relação às possibilidades jurídicas.

A proporcionalidade em sentido estrito, em síntese, refere-se ao sopesamento entre a intensidade do direito fundamental atingido $\left(\mathrm{F}_{1}\right)$ e a importância do direito fundamental que com ele colide $\left(\mathrm{F}_{2}\right)$. Nesse ponto, Alexy (1993, p. 93) pretende que seja perquirida uma relação entre os pesos dos princípios colidentes, onde determinado princípio $\left(\mathrm{P}_{1}\right)$ eventualmente, baseado nas condições do caso concreto, tenha precedência $(P)$ em relação ao princípio colidente $\left(\mathrm{P}_{2}\right)$.

A máxima parcial da proporcionalidade em sentido estrito, por essas razões, propõe que determinado caso seja apreciado por meio de uma lógica de sopesamento racional entre os direitos fundamentais colidentes, onde os motivos de precedência de um dos princípios de direitos fundamentais colidentes, fundamentem a consequência jurídica da não adoção de outros princípios de direitos fundamentais. (SILVA, 2002, p. 40-41). Esses princípios terão, consequentemente, seus efeitos de intensidade restringidos na análise das condições do caso concreto.

É evidente que ao analisar casos envolvendo a colisão de princípios constitucionais, os julgadores encontram uma gama muito maior de elementos problemáticos do que simplesmente questões estruturais de raciocínio que são absorvidas pela aplicação da máxima da proporcionalidade, ou seja, de simples questões envolvendo premissas de ordem teórico-estrutural.

Desse modo, ao enfrentar casos concretos os julgadores se deparam com questões de ordem argumentativa (internas e externas à máxima da proporcionalidade), bem como questões procedimentais coadunadas com outros problemas jurídicos-filosóficos. Essa complexidade combinatória está presente em todos os casos que tratam acerca do dever das ações positivas do Estado para fins de promoção dos direitos fundamentais.

A promoção de direitos fundamentais, com efeito, está diretamente vinculada não só à atuação do Poder Judiciário, mas também ao Legislativo e Executivo. Essa tripartição leva a distintos posicionamentos sobre o devido 
alcance dos direitos fundamentais, bem como pode ser responsável por concretizar ingerências de ordem arbitrária entre os Poderes.

Nessa linha de pensamento, defende-se que o debate científico sobre os limites da aplicação de princípios constitucionais para solução de casos concretos, sobretudo em face do crescimento da utilização e aplicação da Teoria de Alexy, mostra-se uma questão controvertida da discussão doutrinária nas últimas décadas.

Apresentada a base metodológica da aplicação da proporcionalidade, na sequência deste trabalho o objetivo será discutir a aplicação da proporcionalidade em decisão judicial do Tribunal Regional Federal da $4^{\mathrm{a}}$ Região, utilizada como exemplo paradigma que, em pequena medida, enfrentou questionamentos acerca da violação da máxima da proporcionalidade e de suas máximas parciais no âmbito do Direito Negocial.

\section{A PROPORCIONALIDADE COMO LIMITE JURÍDICO DE PROTEÇÃO DOS DIREITOS FUNDAMENTAIS}

Em primeiro lugar, salienta-se que para o presente trabalho interessa os fundamentos da decisão judicial estudada que versam sobre a violação da máxima da proporcionalidade, sobretudo da perspectiva dos elementos e questões envolvendo o Direito Negocial.

Nesse sentido, a ideia da máxima da proporcionalidade foi destaque no Tribunal Regional Federal da $4^{\mathrm{a}}$ Região no tempo em que esse órgão enfrentou o julgamento da apelação cível n n 0026898-63.2008.404.7100/RS. (BRASIL, 2010). O mencionado recurso, interposto pelo Sindicato Interestadual da Indústria do Tabaco (SINDITABACO) em face da Agência Nacional de Vigilância Sanitária (ANVISA), estava fundado no artigo $1^{\circ}$, inciso IV, artigo $5^{\circ}$, inciso IV e IX, e artigo 170, inciso IV, todos da Constituição Federal de 1988.

Entre outras questões, o recurso buscava provimento jurisdicional que assegurasse às fabricantes de cigarros o direito de não apresentar, nas embalagens de seus produtos, as imagens e respectivas cláusulas previstas na Resolução da Diretoria Colegiada da ANVISA (RDC) no 54, de 6 de agosto de 2008. (BRASIL, 2008).

A Resolução da Diretoria Colegiada $n^{\circ} 54 / 08$, alterou a Resolução da Diretoria Colegiada $n^{\circ} 335$, de 21 de novembro de 2003 (BRASIL, 2003), a qual passou a estabelecer que toda divulgação de produtos derivados do tabaco 
deveria ser acompanhada de uma série de advertências transcritas de forma simultânea ou em sequência, de forma legível e ostensivamente destacadas. Tais advertências deveriam vir acompanhadas por imagens, disponibilizadas no site da ANVISA, sendo, também, precedidas da afirmação $O$ Ministério da Saúde adverte.

O Sindicato Interestadual da Indústria do Tabaco, com efeito, postulou que a resolução ( $\operatorname{RDC}^{\circ}$ 54/2008) violava o princípio da proporcionalidade, porque suas determinações não respeitavam as máximas parciais da adequação, necessidade e proporcionalidade em sentido estrito (BRASIL, 2008).

A resolução não estaria compatível com o teste da máxima parcial da adequação, porque as imagens disponibilizadas pelo Ministério da Saúde eram, segundo a entidade apelante, exageradas, também fantasiosas, não correspondendo em nada aos casos reais vivenciados por pessoas consumidoras do cigarro. (BRASIL, 2010).

Por outro lado, também a resolução estaria incompatível com o exame da necessidade, porque, segundo os argumentos da apelante, as imagens disponibilizadas corresponderiam apenas às situações extremas, ou seja, poderiam ser utilizadas outras imagens menos gravosas para atender a finalidade de informar e advertir a população. (BRASIL, 2010).

Ainda, as medidas utilizadas pela resolução contrariavam a proporcionalidade em sentido estrito, porque os benefícios gerados, qual seja a informação mínima à sociedade sobre os prejuízos do fumo à saúde, não compensariam às restrições impostas às industrias do tabaco, tendo em vista que supostamente estas restrições anulariam o direito fundamental das indústrias de promover seus produtos. (BRASIL, 2010).

As medidas governamentais, de outra parte, interfeririam na esfera da autonomia privada, violando, inclusive, o direito difuso dos cidadãos de receber informações verídicas. Logo, as imagens teriam o fim único de causar aversão ao cigarro, sem exatamente orientar de modo legítimo a sociedade acerca dos malefícios do fumo. (BRASIL, 2010).

Ao apreciar as alegações supramencionadas, o Tribunal primeiramente assentou a existência do caráter informativo das imagens e frases escolhidas na Resolução da Diretoria Colegiada ${ }^{\circ} 54 / 2008$ e, com base nos fundamentos constitucionais dispostos no artigo $220, \S 3^{\circ}$, inciso II, e $\S 4^{\circ}$, julgou que a alegação de inadequação não deveria prosperar. 
Melhor dizendo, o não êxito da alegação da violação da máxima parcial da adequação, segundo a decisão judicial em estudo, fundou-se no argumento que a utilização de imagens impactantes, mesmo que fantasiosas, diz respeito à mera consideração pessoal de cada indivíduo, cuidando-se de fator constituinte da tomada pessoal de decisões, ou seja, que pertenceria ao campo do raciocínio moral de cada pessoa. (BRASIL, 2010).

Com relação à violação da necessidade, observou o Tribunal que não havia nos autos qualquer indicação de meios alternativos, menos gravosos à liberdade da propaganda do tabaco que os escolhidos pelo Estado. Incumbência, inclusive, que deveria ter sido sanada pela entidade apelante. (BRASIL, 2010).

Rejeitada a alegação da violação da adequação e da necessidade, o Tribunal enfrentou as alegações no tocante à proporcionalidade em sentido estrito. Essa, segundo o Tribunal (BRASIL, 2010), também foi respeitada porque a defesa da sociedade por meio de advertências e imagens (acerca dos prejuízos decorrentes do consumo do tabaco) seria um objetivo constitucional relacionado diretamente aos direitos fundamentais à vida, à saúde e ao meio ambiente.

Nesse trilhar, fundamentou o Tribunal que o exercício da liberdade publicitária, por um lado, é um princípio constitucional valioso, mas, de outro lado, a Constituição admitiu restrições à liberdade de expressão comercial. (BRASIL, 2010). Portanto, a Constituição já teria realizado uma espécie de ponderação prévia, dando precedência a adoção de medidas fortes pelo Estado para conter o consumo de produtos nocivos.

Concluiu o julgado que, especialmente diante da constatação de que o tabaco é fator de ruidosos prejuízos à saúde da sociedade, deveria prevalecer as medidas Estatais de assistência à saúde pública, uma vez que este meio oferece a mais alta satisfação do princípio que impõe ações positivas do Estado. (BRASIL, 2010).

Apresentada a análise do caso, percebe-se que o uso da proporcionalidade limitou à liberdade de expressão comercial, porque a Constituição dispõe da liberdade de expressão com restrições, visando proteger, no caso concreto, a saúde dos indivíduos. Essa posição constitucional, defendida no caso, revela a defesa dos direitos fundamentais e a preocupação da ordem constitucional com outros valores além da categoria da liberdade comercial. 
Do mesmo modo, quanto à livre iniciativa e à intervenção do Estado no direito privado, preponderaram outros valores constitucionais, por exemplo, a proteção à saúde e o dever de informação da nocividade do tabaco. Essa sobreposição de valores é necessária, por um lado, a partir da necessidade de pensar o Direito Negocial como matéria limitada aos direitos fundamentais, por outro, no reconhecimento do impacto do uso do cigarro na saúde da atual geração e na condição de vida das gerações futuras.

Aliás, romper com o paradigma das práticas econômicas, avançando pelo caminho da inclusão de outras vertentes no pensamento jurídico contemporâneo, é o fundamento de relação equilibrada entre crescimento econômico e desenvolvimento equilibrado.

A apresentação da análise desse caso paradigma, portanto, conduz ao entendimento que há um limite do Direito para a liberdade dos negócios jurídicos e para o desenvolvimento econômico, sobretudo a depender de como a sociedade valoriza a vida das gerações que estão por vir. Logo, reconhecese que a Constituição permite interferência estatal diante de publicidade de produto prejudicial à saúde, bem como dispõe acerca de restrição legal à propaganda comercial de tabaco.

Desse modo, havendo interesse mínimo da sociedade a esse tema, a síntese do problema discutido surge o dever de equilibrar ou diminuir o nível de consumo de produtos nocivos à saúde. Essa prática pressupõe uma modificação de valores sociais, bem como um comportamento na contrapartida do comportamento atual das frentes econômicas.

\section{CONSIDERAÇÕES FINAIS}

A discussão jurídica acerca dos limites da intervenção do Estado nas práticas de direito privado deve seguir uma dicção constitucional e, por sua vez, o Direito Negocial deve ser adaptado às normas constitucionais e ao conforto dos direitos fundamentais.

Por outro lado, a busca pela proporcional aplicação dos princípios constitucionais, por meio da máxima da proporcionalidade, mostra-se um dos desejos mais desafiadores na promoção de garantias fundamentais, porque esses aspectos perpassam por uma aplicação rigorosa e fundamentada da Teoria dos Direitos Fundamentais de Robert Alexy.

Essa busca é certamente um dos principais desafios do Direito, especialmente no âmbito das decisões judiciais envolvendo direitos 
fundamentais. A atuação da jurisdição em casos constitucionais, ao passo que deve cuidar da realização e proteção de direitos fundamentais, tem o dever de evitar a utilização e aplicação errônea de teorias estrangeiras.

Nesse sentido, cumpre mencionar que a decisão analisada reuniu uma fundamentação ínfima acerca da máxima da proporcionalidade, muito aquém das questões trabalhadas pela doutrina de Alexy, uma vez que não houve fundamentação capaz de observar o rigor metodológico proposto pela referida doutrina. Logo, o Tribunal Regional Federal da $4^{\mathrm{a}}$ Região não aplicou as razões da máxima da proporcionalidade com base na Teoria dos Direitos Fundamentais, em verdade decidiu conforme critérios e preceitos de outras naturezas.

Por conseguinte, não se pode deixar de reconhecer, que a aplicação da proporcionalidade no âmbito da decisão estudada pecou por não vir acompanhada de uma rigorosa argumentação, capaz de justificar em termos mínimos a decisão judicial acerca da precedência de determinados direitos fundamentais, sustentando, inclusive, as premissas jurídicas capazes de dar suporte à decisão judicial.

Como já referido anteriormente, reconhece-se o acerto da decisão quanto a matéria discutida no mérito, especialmente em face da necessidade de proteção da saúde pública e da difusão de informações quanto as possíveis doenças oriundas dos produtos provenientes do tabaco, porém defende-se incorreta e insuficiente a utilização da máxima da proporcionalidade nas suas premissas teóricas para justificar e argumentar pela defesa dos princípios e direitos fundamentais.

Com efeito, faz sentido as críticas promovidas pela doutrina brasileira quanto à utilização indevida de teorias importadas no âmbito do Direito pátrio, sobretudo porque os Tribunais ou não aplicam as doutrinas com o rigor metodológico originário ou desconsideram a hipótese da incompatibilidade metodológica de teorias importadas com o ordenamento jurídico brasileiro.

Não obstante, o perigo de ajustar as teorias jurídicas conforme interferências de outras ordens, em essência, trata da problemática acerca da discricionariedade judicial e seus efeitos nocivos à democracia, uma vez que não faz bem às bases democráticas o uso ilimitado, por parte dos julgadores, de poderes capazes de dar sentido à Constituição conforme suas próprias convicções.

Conclui-se, portanto, que a utilização da máxima da proporcionalidade e das máximas parciais como construção da proteção dos direitos fundamentais, 
por parte dos Tribunais brasileiros, é um perigoso espaço para utilização de argumentos teóricos subjetivos, os quais não correspondem à necessária estabilidade do sistema jurídico constitucional brasileiro.

\section{REFERÊNCIAS}

ALEXY, Robert. A construção dos direitos fundamentais. In: TRIVISONNO, Alexandre Trevessoni Gomes (Org.). Teoria discursiva do direito. Rio de Janeiro: Forense Universitária, 2014.

ALEXY, Robert. Teoria de los derechos fundamentales. Tradução de Ernesto Garzón Váldes. Madri: Centro de Estudios Constitucionales, 1993.

BRASIL. Argüição de Descumprimento De Preceito Fundamental $\mathbf{n}^{0}$ 54/DF. Requerente: Confederação Nacional dos Trabalhadores na Saúde CNTS. Requerido: Presidente da República. Relator: Marco Aurélio. Brasília, 12 de abril de 2012. Disponível em: <http://redir.stf.jus.br/ paginadorpub/paginador.jsp? doctp $=$ tp $\&$ docID $=3707334>$. Acesso em: 24 set. 2014.

. Resolução da Diretoria Colegiada n. ${ }^{\circ} 335$, de 21 de novembro de 2003. Revoga as RDC n ${ }^{\circ} 104$ de 31 de maio de 2001 e RDC $n^{\circ} 14$ de 17 de janeiro de 2003. Disponível em: $<$ http://

portal.anvisa.gov.br/wps/wcm/connect/ a4190e $00474597559 \mathrm{fdedf3fbc4c67}$ 35/2003-11-21_Resolu\%C3\%A7\%C3\% A3o+RDC+ 335_Embalagens+e+ Propaganda_21Nov03_OK_PDF.pdf?MOD=AJPERES $>$ Acesso em: 22 jul. $201 \overline{4}$.

\section{. Resolução da Diretoria Colegiada da ANVISA (RDC) no 54,} de 6 de agosto de 2008. Altera a RDC $n^{\circ} 335$, de 21 de novembro de 2003, que dispõe sobre as embalagens de produtos fumígenos derivados do tabaco. Disponível em: <http://www.anvisa.gov.br/divulga/noticias/2008/ 070808_rdc_54.pdf $>$. Acesso em: 22 jul. 2014.

. Tribunal Regional Federal da $4^{\mathrm{a}}$ Região. Apelação cível $\mathbf{n}^{\mathbf{0}}$ 0026898-63.2008.404.7100/RS. Apelante: Sindicato da Ind/ do Fumo no Estado do Rio Grande Do Sul. Apelado: Agência Nacional De Vigilância 
Sanitária - ANVISA. Relator: Des. Federal Marga Inge Barth Tessler. Porto Alegre, 23 de março de 2010. Disponível em: <http://jurisprudencia. trf4.jus.br/pesquisa/pesquisa.php?tipo=1>Acesso em: 22 jul. 2014.

CAPRA, Frijotf. The hidden connections: integrating the biological, cognitive, and social dimensions of life into a science of sustainability. New York: Doubleday, 2002.

GOYARD-FABRE, Simone. Os fundamentos da ordem jurídica. Tradução de Irene A. Paternot. São Paulo: Martins Fontes, 2002.

LA TORRE, Massimo. Nine critiques to Alexy's theory of fundamental rights. In: MENÉNDEZ, Augustín Jóse; ERIKSEN, Erik Oddvar (Ed.). Arguing fundamental rights. Dordrecht: Springer, 2006.

MIRANDA, Jorge. Manual de direito constitucional: direitos fundamentais. 5. ed. Coimbra: Coimbra, 2012.

MORAIS, Fausto Santos. Descobrindo o pressuposto hermenêutico do princípio da proporcionalidade. Revista de Estudos Constitucionais, Hermenêutica e Teoria do Direito, São Leopoldo, v. 6, n. 1, p. 54-62, jun. 2014.

- Hermenêutica e pretensão de correção: uma revisão crítica da aplicação do princípio da proporcionalidade pelo Supremo Tribunal Federal. 2013. 346 f. Tese (Doutorado) - Programa de Pós-Graduação em Direito, Unisinos, São Leopoldo, 2013.

PASOLD, Cesar Luiz. Metodologia da pesquisa jurídica: teoria e prática. 12. ed. São Paulo: Conceito Editorial, 2011.

QUEIROZ, Cristina M. M. Direitos fundamentais: teoria geral. 2. ed. Coimbra: Coimbra Editora, 2010.

SARLET, Ingo Wolfgang. A eficácia dos direitos fundamentais: uma teoria geral dos direitos fundamentais na perspectiva constitucional. 10. ed. Porto Alegre: Livraria do Advogado, 2009. 
SILVA, Luís Virgílio Afonso. O razoável e o proporcional. Revista dos Tribunais, São Paulo, v. 798, p. 23-50, abr. 2002.

STRECK, Lenio Luiz. Jurisdição constitucional e decisão jurídica. 3. ed. São Paulo: Revista dos Tribunais, 2013.

Submetido em: 02/10/2014 Aprovado em: 03/02/2015

Como citar: MORAIS, Fausto Santos de; ZOLET, Lucas Augusto da Silva. A proporcionalidade como limite jurídico ao direito negocial. Scientia Iuris, Londrina, v.19, n.1, p.149-166, jun.2015. 